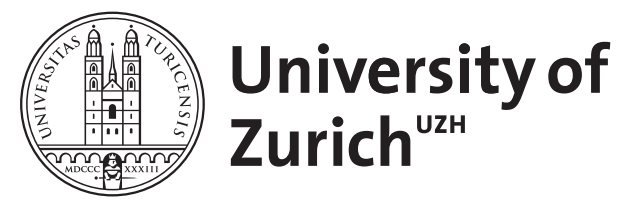

\title{
Cushing syndrome after bilateral lensectomy
}

\author{
Scherrer, Karin Sofia ; Weitz, Marcus ; Eisenack, Johannes ; Truffer, Béatrice ; Konrad, Daniel
}

\begin{abstract}
Iatrogenic Cushing syndrome induced by oral and parenteral corticosteroid administration is a well-known complication, and necessary precautions have to be taken. Cushing syndrome, however, following treatment with glucocorticoid-containing eye drops is a very rare complication. To the best of our knowledge, there have been only four reported cases in the literature. Herein, we present an infant boy who developed Cushing syndrome after receiving dexamethasone-containing eye drops after bilateral cataract extraction to prevent postoperative inflammatory complications. At the age of 5 months, after approx. 3 months of dexamethasone therapy, the patient presented with cushingoid facies, nephrocalcinosis and failure to grow. Iatrogenic Cushing syndrome was diagnosed and dexamethasone-containing eye drops were reduced and eventually stopped. Follow-up examinations revealed catch-up growth.
\end{abstract}

DOI: https://doi.org/10.1007/s00431-014-2477-1

Posted at the Zurich Open Repository and Archive, University of Zurich

ZORA URL: https://doi.org/10.5167/uzh-110719

Journal Article

Published Version

Originally published at:

Scherrer, Karin Sofia; Weitz, Marcus; Eisenack, Johannes; Truffer, Béatrice; Konrad, Daniel (2015). Cushing syndrome after bilateral lensectomy. European Journal of Pediatrics, 174(3):399-401.

DOI: https://doi.org/10.1007/s00431-014-2477-1 


\title{
Cushing syndrome after bilateral lensectomy
}

\author{
Karin Sofia Scherrer • Marcus Weitz • \\ Johannes Eisenack • Béatrice Truffer • Daniel Konrad
}

Received: 5 November 2014 /Revised: 9 December 2014 / Accepted: 10 December 2014 / Published online: 24 December 2014

(C) Springer-Verlag Berlin Heidelberg 2014

\begin{abstract}
Iatrogenic Cushing syndrome induced by oral and parenteral corticosteroid administration is a well-known complication, and necessary precautions have to be taken. Cushing syndrome, however, following treatment with glucocorticoidcontaining eye drops is a very rare complication. To the best of our knowledge, there have been only four reported cases in the literature. Herein, we present an infant boy who developed
\end{abstract}

Communicated by Beat Steinmann

\section{K. S. Scherrer}

General Paediatrics, University Children's Hospital, 8032 Zurich, Switzerland

e-mail: karin.scherrer@kispi.uzh.ch

K. S. Scherrer $\cdot$ M. Weitz $\cdot$ D. Konrad

Children's Research Centre, University Children's Hospital, 8032 Zurich, Switzerland

M. Weitz

e-mail: marcus.weitz@kispi.uzh.ch

\section{Weitz}

Division of Paediatric Nephrology, University Children's Hospital, 8032 Zurich, Switzerland

\section{J. Eisenack}

Department of Paediatric Ophthalmology, University Hospital, 8006 Zurich, Switzerland

e-mail: johannes.eisenack@usz.ch

\section{B. Truffer}

Kinderarztzentrum Kloten AG, 8302 Kloten, Switzerland

e-mail: praxis.truffer@hin.ch

D. Konrad $(\bowtie)$

Department of Endocrinology and Diabetology, University Children's Hospital, Steinwiesstrasse 75, 8032 Zurich, Switzerland

e-mail: daniel.konrad@kispi.uzh.ch
Cushing syndrome after receiving dexamethasone-containing eye drops after bilateral cataract extraction to prevent postoperative inflammatory complications. At the age of 5 months, after approx. 3 months of dexamethasone therapy, the patient presented with cushingoid facies, nephrocalcinosis and failure to grow. Iatrogenic Cushing syndrome was diagnosed and dexamethasone-containing eye drops were reduced and eventually stopped. Follow-up examinations revealed catch-up growth.

Conclusion: Ocularly administered corticosteroids may have substantial systemic side effects in infants.

Keywords Iatrogenic Cushing syndrome $\cdot$ Lensectomy · Glucocorticoid-containing eye drops $\cdot$ Nephrocalcinosis

\section{Abbreviations \\ ACTH Adrenocorticotropic hormone}

\section{Introduction}

Cushing syndrome is the result of prolonged exposure to inappropriately high levels of endogenous or exogenous (iatrogenic) glucocorticoids. The latter is most commonly induced by prolonged exogenous oral or parenteral administered glucocorticoid hormones and represents the most frequent form of Cushing syndrome in children. However, iatrogenic Cushing syndrome in infants due to topical glucocorticoid administration is rare and may be underreported $[10,12]$.

Topical steroids have a wide application in the treatment of postoperative ocular inflammations. Congenital cataract is one of the few visually handicapping disorders that is amenable to early lensectomy but requires postoperative topical steroid treatment in order to prevent fibrinous uveitis. Cushing syndrome as a result of topical ocular steroids is extremely rare, and we are aware of only four reported cases in infancy and 
Table 1 Dexamethasone dose application over time

\begin{tabular}{llll}
\hline $\begin{array}{l}\text { Weeks after } \\
\text { cataract extraction }\end{array}$ & $\begin{array}{l}\text { Dexamethasone } \\
\text { dose (drop/eye/day) }\end{array}$ & $\begin{array}{l}\text { Dexamethasone } \\
\text { dose (mg/day) }\end{array}$ & $\begin{array}{l}\text { Cortisol } \\
\text { equivalent } \\
\left(\mathrm{mg} / \mathrm{m}^{2}\right)\end{array}$ \\
\hline $0-2$ & 12 & 1.3 & 94 \\
$3-4$ & 6 & 0.7 & 47 \\
$5-6$ & 5 & 0.6 & 39 \\
$7-8$ & 4 & 0.4 & 33 \\
$9-10$ & 3 & 0.3 & 24 \\
$11-14$ & 2 & 0.2 & 16 \\
\hline
\end{tabular}

childhood [3, 8, 9, 11]. Herein, we present a case of iatrogenic Cushing syndrome in a 5-month-old infant induced by dexamethasone-containing eye drops.

\section{Case report}

The patient was born at term (37 3/7 weeks of gestation) after an uneventful non-identical twin pregnancy with isolated bilateral nuclear cataract of unknown aetiology (no cataract was observed in his twin sister). He was an otherwise healthy newborn with normal intrauterine growth (birth weight, $2840 \mathrm{~g}$; birth length, $49 \mathrm{~cm}$ ) without evidence for congenital infection. Bilateral cataract extraction was performed at the age of 6 weeks to improve visual prognosis. Immediately after uncomplicated surgery, he was started on dexamethasone-containing eye drops $(0.1 \%$ solution) to prevent fibrinous uveitis. He received one drop per eye every $2 \mathrm{~h}$ for the first 2 weeks; thereafter, dexamethasone dose was tempered as shown (Table 1).

Fig. 1 a Longitudinal growth and weight curves of the patient. $\mathbf{b}$ Patient at the age of 3 months (2 months under dexamethasone treatment; left) and at the age of 1 year (right). Consent to show photographs was obtained from both parents
At the age of 3 months, breastfeeding was stopped and adapted formula milk was introduced instead. One month later, he progressively started to refuse nutrition, resulting in gradual stagnation of growth parameters (Fig. 1a). At 5 months of age, the boy was hospitalized for acute viral gastroenteritis. On physical examination, both body weight and length were below the third percentile. He presented with prominent chubby plethoric cheeks (Fig. 1b) and light hair growth on ears and scrotum. His blood pressure was normal $(101 / 59 \mathrm{mmHg})$. Unfortunately, bone age was not determined. Laboratory evaluation revealed normal sodium $(138 \mathrm{mmol} / \mathrm{l})$ and potassium (4.6 mmol/l) levels, low cortisol (morning, $5 \mathrm{nmol} / \mathrm{l}$; afternoon, $3 \mathrm{nmol} / \mathrm{l}$; reference range $>64 \mathrm{nmol} / \mathrm{l})$ and adrenocorticotropic hormone $(\mathrm{ACTH})$ levels $(10 \mathrm{pg} / \mathrm{ml}$; reference range, $10-55 \mathrm{pg} / \mathrm{ml}$ ). In the context of diagnostic, workup for the patient's failure to thrive abdominal ultrasonography was performed, which revealed nephrocalcinosis in both kidneys and left-sided hydronephrosis. Despite extensive search for diseases associated with nephrocalcinosis, aetiology could not be elucidated. All these findings led to the diagnosis of iatrogenic Cushing syndrome. Consequently, dosage of dexamethasone drops was reduced and eventually stopped (Table 1). At the age of 12 months, he showed catch-up growth (Fig. 1a) and absence of cushingoid features (Fig. 1b). On laboratory evaluation, ACTH (58 pg/ml) and cortisol (319 nmol/l) levels were normalized.

\section{Discussion}

The diagnosis of iatrogenic Cushing syndrome may be fairly obvious in patients receiving systemic administration of

B

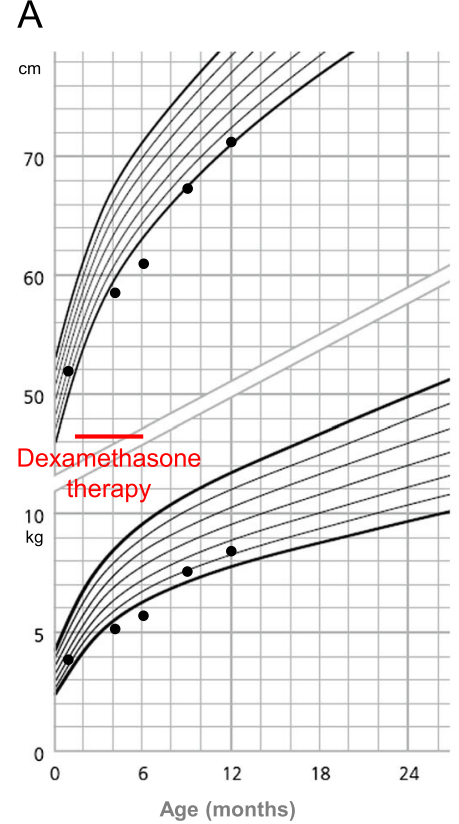

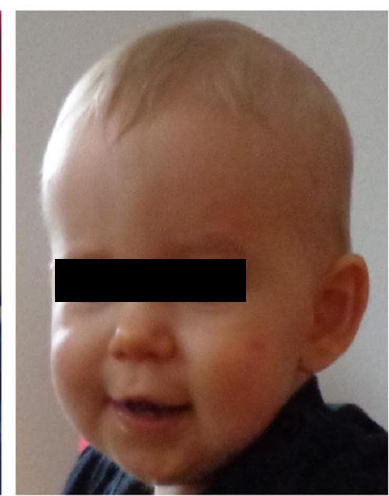

3 months
1 year 
glucocorticoids. However, it may be much more difficult in children treated with locally delivered steroids, e.g., by inhalation or in dermatological preparations $[5,10]$. Cushing syndrome as a result of topical ocular steroids is a rare and probably underreported complication in infants and children. To the best of our knowledge, only four cases have been reported $[3,8,9,11]$ [PubMed was searched for the following keywords: ((("Cushing Syndrome"[Mesh] OR (Cushing AND Syndrome)) AND ((“Ophthalmic Solutions”[Mesh] OR "Ophthalmic Solutions" [Pharmacological Action] OR (Ophtalmic AND Solutions) OR (eye AND drops)) AND ("Glucocorticoids"[Mesh] OR Glucocorticoids))]. There are several ophthalmologic indications for topical ocular steroid treatment in children, one of the most important being the postoperative care after lensectomy in infants with congenital cataract. In order to prevent serious intraocular inflammations like fibrinous uveitis, which is more common in infants than in adults, frequent application of glucocorticoid-containing eye drops is essential. An intense therapy scheme is often pursued for weeks to months. Systemic absorption of glucocorticoidcontaining eye drops depends on drug concentration, chemical formulation and composition of the vehicle. In general, mucous membranes including the conjunctiva are highly absorptive areas. In addition, ocular drops are not only absorbed by the conjunctiva but also by the nasal mucosa via lacrimal drainage system [7]. Of note, systemic absorption of mydriatic eye drops (phenylephrine or cyclopenthale) associated with arterial hypertension or generalized seizures was previously reported in children [2, 4].

Our patient received standard dexamethasone-containing eye drops of $0.1 \%(1.1 \mathrm{mg} / \mathrm{ml})$. For the first 2 weeks of treatment, the approximate daily dose was $1.3 \mathrm{mg}$ dexamethasone per day $\left(\sim 5.2 \mathrm{mg} / \mathrm{m}^{2}\right)$ corresponding to a cortisol equivalent of $\sim 100 \mathrm{mg} / \mathrm{m}^{2}$ (Table 1). In comparison, endogenous cortisol secretion rate in healthy infants/children is estimated to be between 6 and $14 \mathrm{mg} / \mathrm{m}^{2}$ per day [6]. A decrease in growth velocity is observed as soon as daily dosages exceed a cortisol equivalent of 20 to $25 \mathrm{mg} / \mathrm{m}^{2} / 24 \mathrm{~h}$ [1]. Indeed, growth velocity in our patient dropped early after initiation of ocular dexamethasone treatment resulting in a height below the third percentile.

In conclusion, topical steroid preparation may cause iatrogenic Cushing syndrome. Therefore, physicians prescribing topical steroids should be aware of such complication and closely follow these patients. Moreover, withdrawal from long-term treatment may cause adrenal insufficiency demanding a careful weaning of topical steroids.

Acknowledgments We would like to thank Dr. Franziska Kunz and Prof. Dr. Felix H. Sennhauser for critical reading and discussion of the manuscript.

\section{References}

1. Bertrand J, Rappaport R, Sizonenko PC (1993) Pediatric endocrinology: physiology, pathophysiology and clinical aspects. Williams \& Wilkins, Baltimore

2. Borromeo-McGrail V, Bordiuk JM, Keitel H (1973) Systemic hypertension following ocular administration of 10 per cent phenylephrine in the neonate. Pediatrics 51:1032-1036

3. Chiang MY, Sarkar M, Koppens JM, Milles J, Shah P (2006) Exogenous Cushing's syndrome and topical ocular steroids. Eye 20:725-727

4. Demayo AP, Reidenberg MM (2004) Grand mal seizure in a child 30 minutes after Cyclogyl (cyclopentolate hydrochloride) and $10 \%$ Neo-Synephrine (phenylephrine hydrochloride) eye drops were instilled. Pediatrics 113:e499-e500

5. Findlay CA, Macdonald JF, Wallace AM, Geddes N, Donaldson MD (1998) Childhood Cushing's syndrome induced by betamethasone nose drops, and repeat prescriptions. BMJ 317:739-740

6. Kerrigan JR, Veldhuis JD, Leyo SA, Iranmanesh A, Rogol AD (1993) Estimation of daily cortisol production and clearance rates in normal pubertal males by deconvolution analysis. J Clin Endocrinol Metab 76:1505-1510

7. McGhee CN, Dean S, Danesh-Meyer H (2002) Locally administered ocular corticosteroids: benefits and risks. Drug Saf 25:33-55

8. Messina MF, Valenzise M, Aversa S, Arrigo T, De Luca F (2009) Iatrogenic Cushing syndrome caused by ocular glucocorticoids in a child. BMJ Case Rep 2009

9. Ozerdem U, Levi L, Cheng L, Song MK, Scher C, Freeman WR (2000) Systemic toxicity of topical and periocular corticosteroid therapy in an 11-year-old male with posterior uveitis. Am J Ophthalmol 130:240-241

10. Ozon A, Cetinkaya S, Alikasifoglu A, Gonc EN, Sen Y, Kandemir N (2007) Inappropriate use of potent topical glucocorticoids in infants. J Pediatr Endocrinol Metab 20:219-225

11. Romano PE, Traisman HS, Green OC (1977) Fluorinated corticosteroid toxicity in infants. Am J Ophthalmol 84:247-250

12. Tempark T, Phatarakijnirund V, Chatproedprai S, Watcharasindhu S, Supornsilchai V, Wananukul S (2010) Exogenous Cushing's syndrome due to topical corticosteroid application: case report and review literature. Endocrine 38:328-334 